J. Lake Sci. (湖泊科学), 2012, 24(6): 957-964

http: //www. jlakes.org. E-mail : jlakes@niglas.ac.cn

(C) 2012 by Journal of Lake Sciences

\title{
2002 年腾格里沙漠湖泊季节变化研究
}

\author{
来婷婷 ${ }^{1,2}$, 王乃昂 ${ }^{1,2 * *}$, 黄银洲 ${ }^{1,2}$, 张建明 ${ }^{1,2}$, 赵力强 ${ }^{1,2}$, 许洺山 $^{1}$ \\ (1: 兰州大学资源环境学院,兰州 730000$)$ \\ ( 2 : 兰州大学干旱区气候变化与水循环研究中心, 兰州 730000)
}

摘 要: 以 2002 年的 6 期 ETM + 遥感影像作为数据源, 采用面向对象的解译方法, 自动提取腾格里沙漠一年内 6 个时期 的湖泊信息, 对湖泊季节变化情况进行统计, 并与巴丹吉林沙漠的湖泊季节变化进行对比分析. 结果表明, 腾格里沙漠湖 泊的季节变化显著, 湖泊总数量及总面积在夏季 ( 6 月) 达最大值, 在冬季 (12、2 月) 最小; 两大沙漠湖泊季节变化情况不 尽相同, 可能与两大沙漠湖泊水的补给方式存在差异有关, 腾格里沙漠湖泊水量变化更多地受近源地下水的影响, 而巴 丹吉林沙漠湖泊水量变化则主要受远源地下水影响.

关键词: 腾格里沙漠;湖泊; 遥感;季节变化

\section{Seasonal changes of lake in Tengery Desert of 2002}

LAI Tingting ${ }^{1,2}$, WANG Nai' ang $^{1,2}$, HUANG Yinzhou ${ }^{1,2}$, ZHANG Jianming $^{1,2}$, ZHAO Liqiang $^{1,2} \&$ XU Mingshan $^{1}$

(1: College of Earth and Environmental Sciences, Lanzhou University, Lanzhou 730000, P. R. China)

(2: Center for Climate Change and Hydrologic Cycle in Arid Region, Lanzhou University, Lanzhou 730000 , P. R. China)

\begin{abstract}
Based on object-oriented method, six ETM + satellite images of the year 2002 were interpreted and analyzed to study the seasonal change of the lakes in Tengery Desert. Result indicates that lake level changed sharply over the years. That is, both the amount and the area of the lakes in Tengery Desert reached their summits in summer (June), while the lowest amount and level in winter. This phenomenon differs from that of the Badain Jaran Desert, in which the lakes have their high level during winter. The difference to some extent explained the different replenishment patterns between the lakes in two deserts: lakes in Tengery Desert would be recharged by precipitation and adjoining ground water, but those in Badain Jaran Desert would be highly affected by longdistant ground water.
\end{abstract}

Keywords: Tengery Desert; lake; remote sensing; seasonal change

湖泊是地球系统各圈层相互作用的连接点, 它的形成与消失、扩张与收缩及其引起的生态环境的演化 过程都是全球的、区域的和局部的构造和气候事件共同作用的结果 ${ }^{[1]}$. 湖泊水量与水位的变化在一定程度 上表征了水量平衡变化过程及其气候与环境的变化过程 ${ }^{[2]}$. 由于不同时间尺度的湖泊变化往往蕴含着不同 的环境意义,因此有必要开展不同时间尺度的湖泊变化研究. 湖泊年际变化的研究通常从气温、降水等因素 探讨近几十年来局部区域湖泊萎缩或扩张的机理, 明确湖泊变化对于气候变化的响应 ${ }^{[3-6]}$; 湖泊年内变化的 研究旨在探讨受局地降水、蒸发、地下水等综合作用下的湖泊水量变化特征, 这一变化是当地湖泊补给方式 的重要表征. 在干旱少雨的沙漠腹地亦存在大量湖泊, 这些湖泊是干旱区不可多得的水源之一, 它们在维持 周边生态环境及当地居民生产生活中作用巨大 ${ }^{[7]}$. 沙漠湖泊的水量变化研究是开展水资源调查、沙漠湖泊 水循环及湖泊水量平衡研究的基础 ${ }^{[8]}$. 及时准确地掌握湖泊季节变化规律是进行沙漠湖泊水源、水循环、湖

* 高等学校博士点专项基金项目 (20090211110025)、国家基础科学人才培养基金项目 ( J1030519)、国家自然科学基 金项目 (41101187) 和国家环保公益性行业科研专项项目 (201209034) 联合资助. 2011-12-08 收稿; 2012 -03-14 收修改稿. 来婷婷,女, 1987 年生, 硕士研究生;E-mail : laitt520@yahoo. cn.

** 通信作者;E-mail:wangna@lzu. edu.cn. 
泊水量平衡等研究的重要前提. 在降水稀少、蒸发强烈的气候背景下, 降水、地下水是沙漠湖泊可能的补给 形式. 不同沙漠内部湖泊面积的季节变化对比分析是区分不同补给方式的有效手段, 有助于深人理解沙漠 湖泊形成和演化过程. 位于阿拉善荒漠区中的腾格里沙漠, 以湖泊众多著称, 关于其内湖泊的季节变化情况 及补给方式尚不明确 ${ }^{[9]}$, 因此选取腾格里沙漠湖泊作为研究对象具有重要意义.

遥感技术在湖泊动态变化研究方面具有十分重要的作用, 在一定程度上推动着湖泊水体计算机自动提 取方法的发展. 传统的应用遥感技术进行的湖泊变化研究 ${ }^{[10-13]}$ 多采用基于像元的分类方法, 如单波段阈值 法、多波段运算法、波段组合法、特征空间转化法及决策树法等 ${ }^{[14]}$. 这些基于像元的水体提取方法只利用像 元的光谱信息, 获得的结果精度低 ${ }^{[15]}$, 且 “椒盐” 现象明显 ${ }^{[16]}$. 近两年, 面向对象的分类方法逐渐开始被国内 外学者使用 ${ }^{[17]}$, 这种方法的处理过程以及算法理论的研究也逐渐深人. 面向对象的分类方法是以最小同质 影像对象为分类最小单元的一种图像分类方法 ${ }^{[18]}$, 将多要素特征引人分类过程, 有效提高了分类精度, 抑制 了 “椒盐” 效应. 腾格里沙漠内的湖泊由于水体 TDS 较高、水深较浅, 因此呈现出独特的光学特性 ${ }^{[19]}$, 且由于 独特的成湖原因, 表现出面积小、形状不规则及形态破碎的特征. 针对腾格里沙漠湖泊这些特点, 相对于传 统的面向像元的分类方法, 此种面向对象的分类方法更适合用于此区域的研究. 基于此, 本文利用一年内 6 期 ETM + 遥感影像, 采用面向对象湖泊自动解译方法, 在提取腾格里沙漠湖泊季节变化信息并对其进行分 析的基础上, 结合同年巴丹吉林沙漠湖泊季节变化数据, 通过分析两大沙漠湖泊季节变化的特征, 初步探讨 了两大沙漠湖泊补给机制的差异性.

\section{1 研究区概况}

腾格里沙漠位于阿拉善地区东南部, 介于贺兰山、祁连山与雅布赖山之间, 面积约为 $4.27 \times 10^{4} \mathrm{~km}^{2}$, 是 中国第四大沙漠 ${ }^{[7]}$. 区内地势总体呈现西南高、东北低的趋势, 海拔 $1100 \sim 2000 \mathrm{~m}$. 沙漠内部沙丘、湖盆、山 地、残丘及平原等交错分布, 其中沙丘占 $71 \%$, 湖盆草滩占 7\%, 山地残丘及平地占 $22 \%$. 沙漠内部分布着众 多湖泊, 大小不等, 形态各异, 除淡水湖泊之外, 还有很多 TDS 高的咸水湖及一定数量的干涸盐碱湖盆. 根据 其分布特点大致分为以下三种类型: 1) 沙漠中南部, 分布呈规则的南北走向平行排列的湖盆, 它们大多可能 是晚第四纪古湖泊 ${ }^{[20]}$ 干涸退缩而形成的残留湖;2) 沙漠西部及南部, 分布呈不规则的湖盆; 3 ) 沙漠中部偏 东北地区, 位于东北西南走向的复合型沙丘链之间的丘间洼地中, 分布呈规则排列的面积较小的湖盆 ${ }^{[7]}$. 根 据沙漠内湖泊分布特征, 沙漠中部偏东地区湖泊区域内湖泊面积小、个数多, 具有典型性, 将此区域作为研 究区能更好地达到研究目的, 由此本文选取中部偏东地区丘间洼地中的湖泊区域进行研究 (图 1).

\section{2 数据源及其预处理}

研究所用的数据为美国地质勘查局 (USGS) 提供的 Landsat-ETM + L1T 级遥感影像. 遥感影像轨道号 (Path/Row) 为 $130 / 33$, 时间为 2002 年 2 月 16 日、4 月 5 日、6月 24 日、8 月 27 日、10月 14 日、12月 17 日,所 选影像云量小于 $1 \%$. 采用 Albers 等积投影对影像进行投影转换, 采用 ENVI Zoom 中的 Pan Sharpening 工具 对影像进行融合处理, 融合后影像空间分辨率为 $15 \mathrm{~m}$, 影像融合、裁剪、投影转换及参数计算借助 ENVI 4.8 图像处理软件完成, 湖泊信息提取借助 eCognition 8.0 图像处理软件完成, 湖泊提取信息核对及变化信息生 成借助 ArcGIS 9.3 完成.

\section{3 研究方法}

\section{1 湖泊界定}

为准确反映研究区内湖泊数量、面积及其分布特征, 在提取湖泊信息之前, 作如下界定: (1) 湖泊指湖 盆内水域覆盖地区, 不包括湖泊内的岛屿、湖泊周围的沼泽化草甸、盐生草甸等植被及干涸盐碱湖盆; (2) 由于湖泊季节性萎缩, 部分湖泊呈现出解体现象, 即一个大湖泊分裂成几个小湖泊, 在湖泊信息后处理 阶段, 将这些分裂的小湖泊合并, 其数量、面积都计人一个湖泊; (3) 冬季湖泊出现结冰现象, 结冰区域亦计 人湖泊面积; (4) 提取面积大于 $900 \mathrm{~m}^{2}$ (4 个像元) 的湖泊.

\section{2 湖泊遥感解译方法}

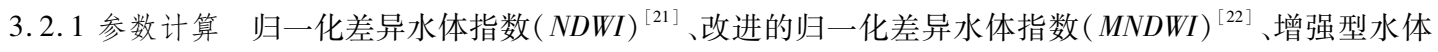




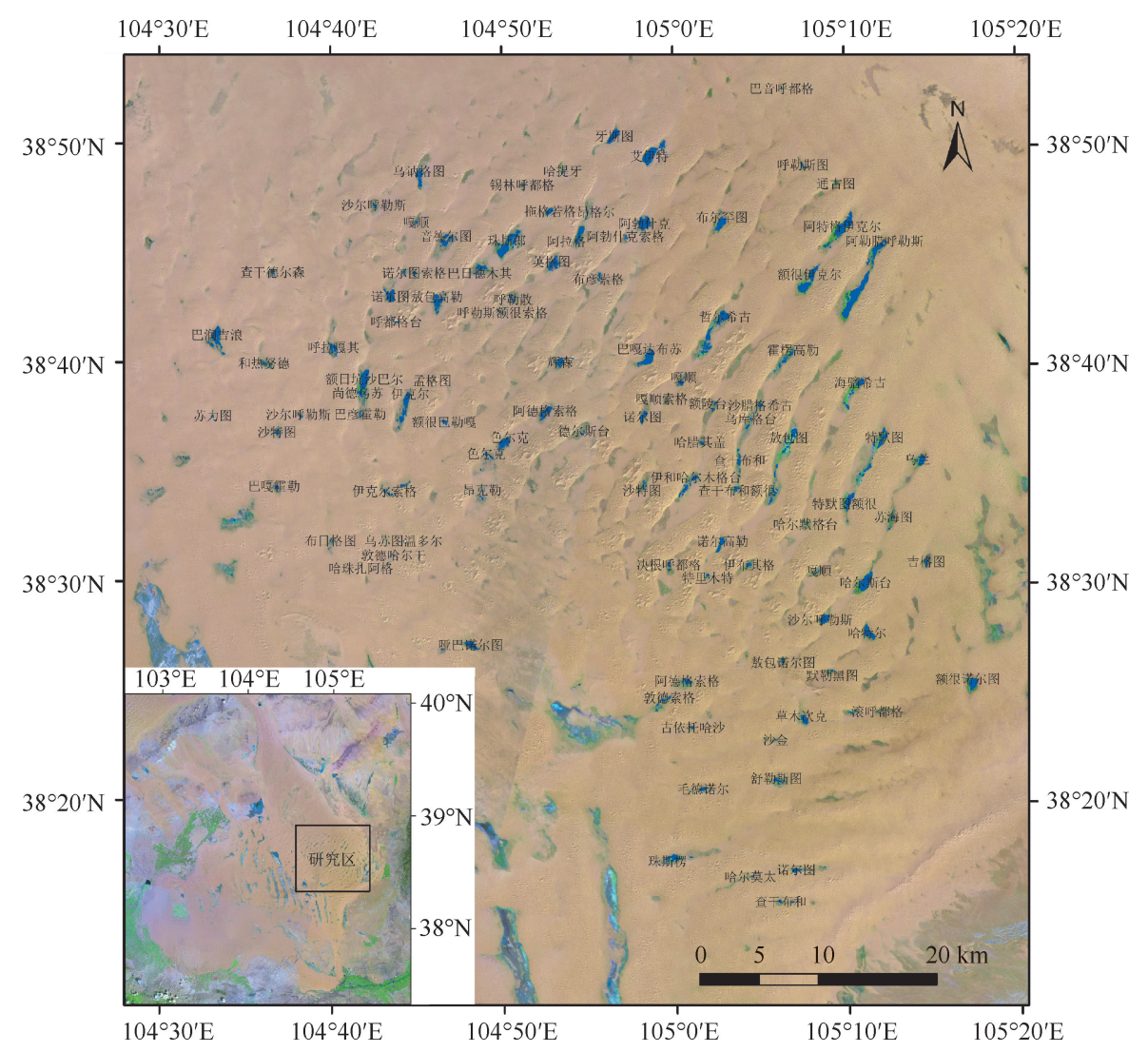

图 1 腾格里沙漠位置及湖泊分布

Fig. 1 Distribution of the lakes in Tengery Desert

指数 $(E W I)^{[23]}$ 、新型水体指数 $(N W I)^{[24]}$ 及沙漠水体指数 $(D L W I)^{[8]}$ 都被应用于水体的自动检测. 为了更好地提取出 沙漠中的湖泊, 要将水体与湖边的沙地、植被以及盐碱进 行区分, 根据波谱曲线 (图 2) 的特点, 选取 $N D W I 、 M N D W I$ 以及 $D L W I$ 进行水体检测试验, 试验结果表明 $D L W I$ 能更准 确地识别出水体信息, 由此最终选定 $D L W I$ 作为湖泊提取 的参数.

$$
D L W I=\left(b_{\text {blue }}-b_{\text {mir }}\right) /\left(b_{\text {blue }}+b_{\text {mir }}\right)
$$

式中, $b_{\text {blue }}$, $b_{\text {mir }}$ 分别代表 ETM + 影像的第 $1 、 5$ 波段的 $D N$ 值.

归一化植被指数 (NDVI) 广泛用于植被的识别. 根据研 究区样点分析发现, 由于影像分辨率限制及湖泊边界情况 复杂的原因, 仅依靠 $D L W I$ 用于水体识别精度较低, 存在部 分植被的混分, 由此引人 $N D V I$, 进一步将植被与水体进行 区分.

$$
N D V I=\left(b_{\text {nir }}-b_{\text {red }}\right) /\left(b_{\text {nir }}+b_{\text {red }}\right)
$$

式中, $b_{\text {red }} 、 b_{\text {nir }}$ 分别代表 $\mathrm{ETM}+$ 影像的第 $3 、 4$ 波段的 $D N$ 值.

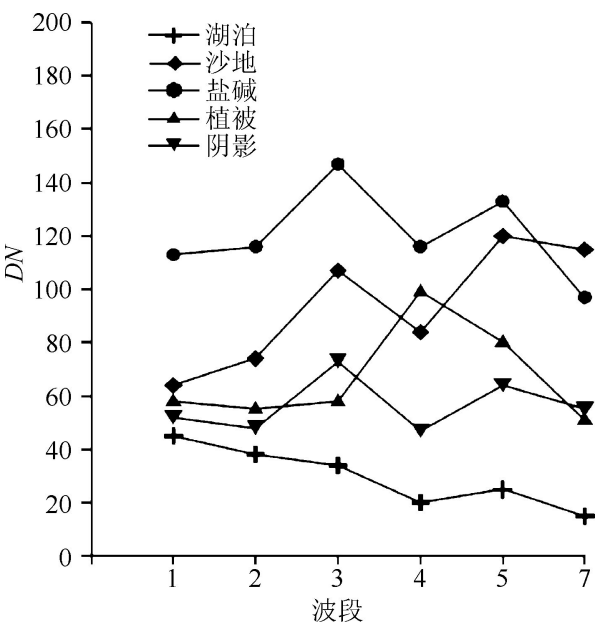

图 2 湖泊、沙地、盐碱、植被、阴影的光谱曲线

Fig. 2 Spectral curves of different landscapes 


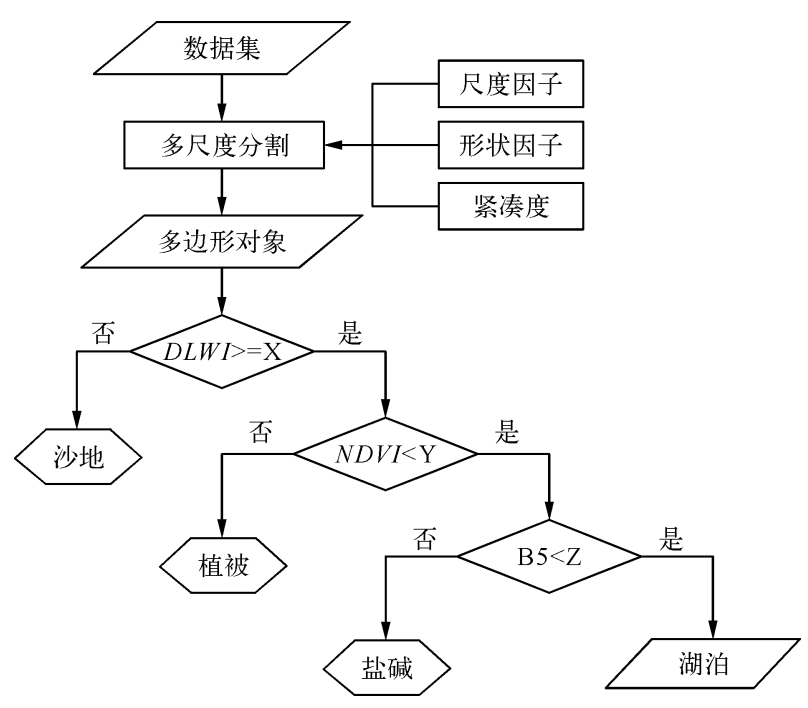

图 3 面向对象方法湖泊提取流程

Fig. 3 Extraction processes of lakes in Tengery Desert based on the object-oriented method

表 1 各时相水体提取國值

Tab. 1 Water extraction threshold of each period

\begin{tabular}{ccccccc}
\hline 提取阈值 & 2 月 & 4 月 & 6 月 & 8 月 & 10 月 & 12 月 \\
\hline$X$ & -0.25 & -0.06 & -0.14 & -0.04 & -0.18 & -0.06 \\
$Y$ & - & 0 & 0 & 0 & 0 & - \\
$Z$ & 76 & 60 & 62 & 76 & 67 & 73 \\
\hline
\end{tabular}

3.2.2 湖泊提取流程 首先, 在影像预处理 的基础上计算关键参数并构建数据集, 即将 $\mathrm{TM}$ 各个波段、DLWI 数据及 $N D V I$ 数据组成 一个数据集. 之后, 采用面向对象方法构建 分类规则, 进行湖泊提取. 其中, 面向对象的 湖泊信息提取是在 eCognition 8.0 平台下实 现, 主要包括三个过程: 影像分割、规则制定 及结果输出. 影像分割是湖泊信息提取的关 键步骤, 选取多尺度分割方法对影像进行分 割, 此分割结果受到尺度因子、形状因子及 紧凑度三个因子的影响, 为了达到准确提取 内部差异性较小的对象的目的, 经过多次试 验, 最终确定出合理的分割阈值.

湖泊信息提取的另一个关键步骤在于 规则的制定, 在对采样区分析试验的基础 上, 选取合理阈值, 从而制定出湖泊提取规 则. 根据对研究区样点的分析发现, 采用多 指数阈值设定逐步剔除非目标要素 (图 3), 最终达到提取目标要素的方法可取得较好 的效果. 直方图是灰度分布的直观体现, 所 以阈值的选取以样点区图像直方图为依据. 为了提高提取的精度, 对于不同的时相采用 不同的阈值 (表 1), 其中冬季植被枯萎, 无 需剔除植被.

在湖泊信息后处理阶段, 以“湖泊界

定”为基础,对获取的湖泊信息结合地形图,进行信息的核查以及修订. 对提取结果存在问题作如下处理:

(1) 去除小于 4 个像元的湖泊; (2) 沙山阴影与湖泊水体存在 “异物同谱” 现象, 目视解译去除沙山阴影.

\section{3 湖泊变化信息生成}

借助 ArcGIS 软件, 将核对后的提取结果生成年内变化信息, 定义年内变化率为:

$$
R=\frac{A_{m}-A_{n}}{A_{n}} \times 100 \%
$$

式中, $A_{m} 、 A_{n}$ 分别表示后一时期和前一时期的湖泊数量或面积, $R>0$ 表示湖泊扩张, $R<0$ 表示湖泊萎缩.

定义变化速率为:

$$
T=\left(\frac{T_{m}-T_{n}}{T_{n}}\right) / n
$$

式中, $T_{m}$ 表示后一时期的湖泊数量或面积, $T_{n}$ 表示前一时期的湖泊数量或面积, $n$ 为月份数.

\section{4 结果分析与讨论}

\section{1 湖泊变化总体特征}

由于降水和地下水对沙漠内湖泊的补给存在较大的季节性差异, 使得腾格里沙漠湖泊随着季节的更替 变化显著 (表 2). 在腾格里沙漠内, 季节型湖泊与非季节型湖泊并存, 其中研究区内非季节型湖泊数量大于 季节型湖泊数量, 非季节型湖泊总面积年内最大变化率接近 $50 \%$ 、湖泊总数量年内最大变化率接近 $30 \%$. 冬 季为湖泊枯水期,春、夏季湖泊水量大于秋季湖泊水量. 


\section{2 湖泊季节变化特征}

夏季 $(6$ 月) 湖泊总数量及总面积均达年内最大 值, 冬季 $(2 、 12$ 月) 湖泊总数量及总面积最小 $($ 表 2$)$. 腾格里沙漠内的湖泊随着季节的更替呈现变化, 26 月湖泊总变化趋势为数量增多, 面积增大. 其中 24 月,湖泊总数量及总面积增加明显; $4-6$ 月, 湖泊 总数量及总面积变化增幅较小. $6-12$ 月, 湖泊总变 化趋势为数量减少,面积减小,其中 $8-10$ 月湖泊总 数量及总面积持续减小,但变化不明显, $10-12$ 月湖 泊总数量及总面积均显著减小. 一年内, 存在两个湖 泊变化相对稳定的时期,分别为 4-6月和 8-10 月. 春、夏季湖泊总数量及总面积比夏、秋季节湖泊总数 量及总面积更大.

由于各期湖泊平均面积、湖泊面积中位数均接近 $0.1 \mathrm{~km}^{2}$, 而面积大于 $1 \mathrm{~km}^{2}$ 或面积小于 $0.01 \mathrm{~km}^{2}$ 的湖 泊数量均较少, 由此根据以上湖泊面积特征, 采取自定义划分方式, 将湖泊分为 $>1 、 0.5 \sim 1 、 0.1 \sim 0.5 、 0.05 \sim$ $0.1 、 0.01 \sim 0.05 、<0.01 \mathrm{~km}^{2}$ 六个等级, 分级名称为一级、二级、三级、四级、五级、六级 (表 3 ). 一级湖泊年内 变化明显, 2-6 月逐渐增加, 6-12 月逐渐减少, 其中 6 月达 5 个而 2 月和 12 月仅有 1 个, 一级湖泊变化趋 势与所有湖泊的年内变化趋势一致;二级湖泊, 数量最多面积最大的时间依次为 4 月、10 月、 8 月、 12 月、 6 月、 2 月, 6 月二级湖泊数量及面积明显偏小, 原因是 6 月湖泊面积扩张, 2 个二级湖泊变为一级湖泊, 而三级 湖泊并未补给为二级湖泊; $4-10$ 月, 面积大于 $0.5 \mathrm{~km}^{2}$ 的湖泊 (一级和二级湖泊) 总数量及总面积变化不 大; 三级湖泊, 2-6 月湖泊总数量增加, 总面积增大, 其中 $2-4$ 月部分五级湖泊扩张为三级湖泊, 6-12 月, 三级湖泊逐渐萎缩, 部分三级湖泊萎缩成五级湖泊; 四级湖泊, $2-4$ 月, 湖泊数量与面积变化明显; 五级湖 泊, $10-12$ 月, 湖泊数量与面积变化明显; 六级湖泊, $2-6$ 月, 湖泊多因干涸湖盆再现水域, $6-12$ 月, 六级湖 泊萎缩甚至干涸.

表 3 腾格里沙漠湖泊分级信息

Tab. 3 Lake classified information in Tengery Desert

\begin{tabular}{|c|c|c|c|c|c|c|c|c|c|c|c|c|}
\hline \multirow{2}{*}{ 月份 } & \multicolumn{2}{|c|}{ 一级湖泊 } & \multicolumn{2}{|c|}{ 二级湖泊 } & \multicolumn{2}{|c|}{ 三级湖泊 } & \multicolumn{2}{|c|}{ 四级湖泊 } & \multicolumn{2}{|c|}{ 五级湖泊 } & \multicolumn{2}{|c|}{ 六级湖泊 } \\
\hline & 数量 & 面积 $/ \mathrm{km}^{2}$ & 数量 & 面积 $/ \mathrm{km}^{2}$ & 数量 & 面积 $/ \mathrm{km}^{2}$ & 数量 & 面积 $/ \mathrm{km}^{2}$ & 数量 & 面积 $/ \mathrm{km}^{2}$ & 数量 & 面积 $/ \mathrm{km}^{2}$ \\
\hline 2 & 1 & 1. 194 & 4 & 2.549 & 28 & 7. 649 & 9 & 0.793 & 25 & 0.759 & 10 & 0.151 \\
\hline 4 & 3 & 4. 302 & 10 & 7.845 & 33 & 8.537 & 16 & 1.503 & 27 & 0.873 & 13 & 0.203 \\
\hline 6 & 5 & 6.300 & 7 & 4.932 & 37 & 10.812 & 16 & 1.136 & 28 & 0.941 & 13 & 0.228 \\
\hline 8 & 2 & 3.014 & 10 & 7.098 & 32 & 8.106 & 17 & 1.371 & 28 & 0.664 & 13 & 0.216 \\
\hline 10 & 2 & 2.912 & 10 & 7.506 & 29 & 7.548 & 13 & 1.118 & 31 & 0.940 & 14 & 0.098 \\
\hline 12 & 1 & 1.360 & 8 & 5.175 & 22 & 5.774 & 14 & 1.100 & 26 & 0.647 & 7 & 0.034 \\
\hline
\end{tabular}

\section{3 腾格里沙漠与巴丹吉林沙漠湖泊季节变化对比分析}

将腾格里沙漠湖泊季节变化情况 (表 2) 与巴丹吉林沙漠湖泊季节变化情况 ${ }^{[8]}$ (表 4) 进行对比分析 (表 5) 可知, 腾格里沙漠湖泊与巴丹吉林沙漠湖泊年内各时期的变化情况不尽相同. 虽然, 腾格里沙漠湖泊与巴 丹吉林沙漠湖泊的年内总变化情况有相同之处, 都表现为冬季为湖泊枯水期,春、夏季水量较充沛. 其中, 腾 格里沙漠湖泊总面积最大、总数量最多的时期为夏季 ( 6 月), 湖泊总面积最小、总数量最少的时期为冬季 (2、12 月), 同时春季 ( 4 月) 湖泊总面积大于秋季 ( $8 、 10$ 月); 巴丹吉林沙漠湖泊总面积最大的时期为春季 ( 3 月), 湖泊总面积最小、总数量最少的时期为冬季 (12 月), 夏季 ( 7 月) 湖泊总面积大于秋季 (9 月). 但是, 腾 格里沙漠湖泊与巴丹吉林沙漠湖泊年内变化情况也存在诸多差异. 1) 一年内, 腾格里沙漠湖泊从冬季进人 春季以及从秋季进人冬季, 湖泊变化最为明显; 而巴丹吉林沙漠湖泊从冬季进入春季湖泊变化明显, 但从秋 季进人冬季湖泊变化却很微弱. 巴丹吉林沙漠湖泊最突出的水量平稳期为 $9-12$ 月, 而腾格里沙漠湖泊在 
表 4 巴丹吉林沙漠湖泊信息提取结果统计

Tab. 4 The statistical results of lakes in Badain Jaran Desert interpreted from Landsat-ETM + images

\begin{tabular}{crrrrr}
\hline \multirow{2}{*}{$\begin{array}{c}\text { 日期 } \\
\text { (年-月 })\end{array}$} & \multicolumn{2}{c}{ 总数量 } & & \multicolumn{2}{c}{ 总面积 } \\
\cline { 2 - 3 } \cline { 5 - 6 } & 数量 & 变化率 $/ \%$ & & 面积 $/ \mathrm{km}^{2}$ & 变化率 $/ \%$ \\
\hline $2001-12$ & 84 & & & 16.98 & \\
$2002-03$ & 109 & 29.76 & & 19.16 & 12.84 \\
$2002-07$ & 95 & -12.84 & & 18.31 & -4.44 \\
$2002-09$ & 87 & -8.42 & & 16.87 & -7.86 \\
$2002-12$ & 84 & -3.45 & & 16.70 & -1.01 \\
\hline
\end{tabular}

10-12 月变化剧烈, 这一现象表明, 由丰水期进 人枯水期, 腾格里沙漠湖泊的萎缩过程不平稳, 而巴丹吉林湖泊的萎缩过程是相对平稳的. 2) 腾格里沙漠湖泊 (数量、面积) 年内最大变率大于 巴丹吉林沙漠湖泊 (数量、面积) 年内最大变率, 腾格里沙漠湖泊对季节更替表现得更为敏感. 腾 格里沙漠湖泊年内最大萎缩数量为 25 个, 占湖 泊最大总数量的 $23.58 \%$, 最大萎缩面积为 11.17 $\mathrm{km}^{2}$, 占湖泊最大总面积的 $45.87 \%$; 巴丹吉林沙 漠湖泊年内最大萎缩数量为 25 个, 占湖泊最大 总数量的 $22.93 \%$, 最大萎缩面积为 $2.46 \mathrm{~km}^{2}$, 占

湖泊最大总面积的 $12.84 \%$.

表 5 腾格里沙漠与巴丹吉林沙漠湖泊季节变化情况对比

Tab. 5 The lake changes contrast in one year between Tengery Desert and Badain Jaran Desert

\begin{tabular}{|c|c|c|c|c|c|}
\hline \multirow{3}{*}{ 时间段 } & \multicolumn{2}{|c|}{ 腾格里沙漠 } & \multirow{3}{*}{ 时间段 } & \multicolumn{2}{|c|}{ 巴丹吉林沙漠 } \\
\hline & \multicolumn{2}{|c|}{ 变化速率 } & & \multicolumn{2}{|c|}{ 变化速率 } \\
\hline & 数量 & 面积 $/ \mathrm{km}^{2}$ & & 数量 & 面积 $/ \mathrm{km}^{2}$ \\
\hline $2-4$ 月 & 12.5 & 5.04 & $12-3$ 月 & 8.33 & 0.72 \\
\hline $4-8$ 月 & 0 & -4.15 & $3-7$ 月 & -3.5 & -0.21 \\
\hline $8-10$ 月 & -1.5 & -0.18 & 7-9月 & -4 & -0.72 \\
\hline $10-12$ 月 & -10.5 & -3.02 & $9-12$ 月 & -1 & 0.06 \\
\hline
\end{tabular}

两个沙漠内湖泊的季节变化情况存在诸多差异, 以距腾格里沙漠最近的阿拉善左旗站和距巴丹吉林沙 漠最近的阿拉善右旗站的降水 (图 4、5) 和蒸发数据(图 6) 为依据(其中蒸发数据由 $1971-2000$ 年小型蒸发 皿观测数据均值乘以折算系数得到 ${ }^{[25]}$ ), 进行分析可知:1) 腾格里沙漠湖泊与巴丹吉林沙漠湖泊在水深、面 积及形态特征等方面存在较大差异, 腾格里沙漠多为水深浅、面积小、形状不规则的湖泊, 而巴丹吉林沙漠 多为水深较深、面积较大、形状较为规则的湖泊, 水深浅、面积小的湖泊对外界环境的变化表现的更为敏感; 2) 全年各月蒸发量远大于降水量, 两个沙漠湖泊的降水补给均不能满足湖面蒸发损耗和水量增加的需要, 因此两大沙漠湖泊应该均存在地下水或其他形式的水源补给;3) 对于腾格里沙漠而言, 一年内, 湖泊水量的 多寡与降水量的高低一致性较好 (与降水量的相关系数为 0.8691 , 与蒸发量的相关系数为 -0.9036 ), 4 月,
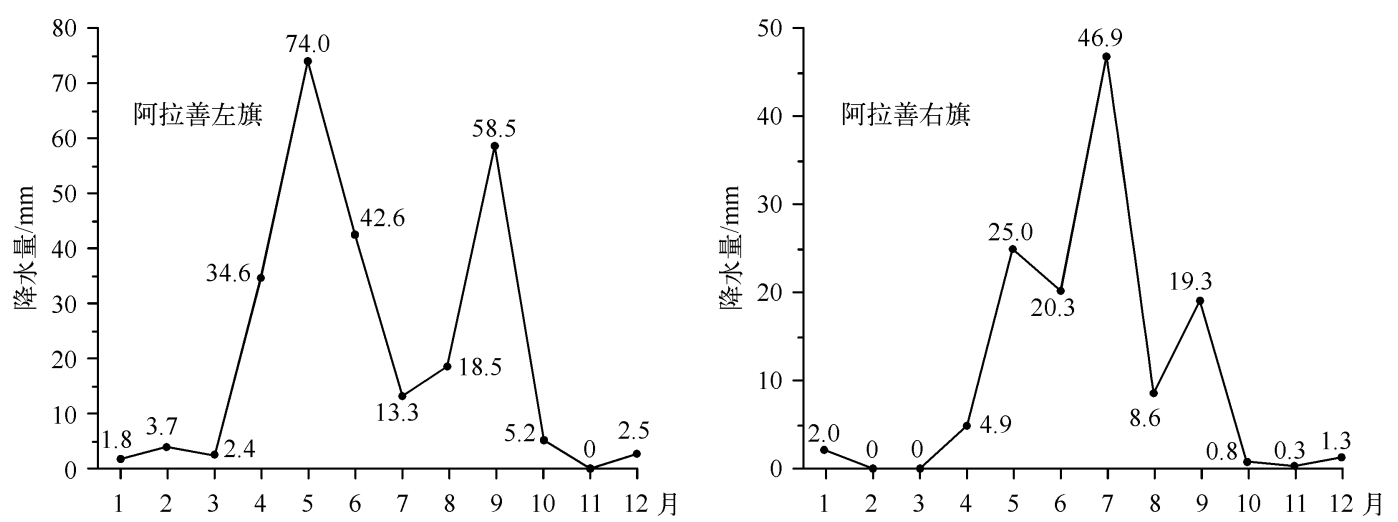

图 4 阿拉善地区 2002 年逐月降水量

Fig. 4 Monthly precipitation of Alashan area in 2002 

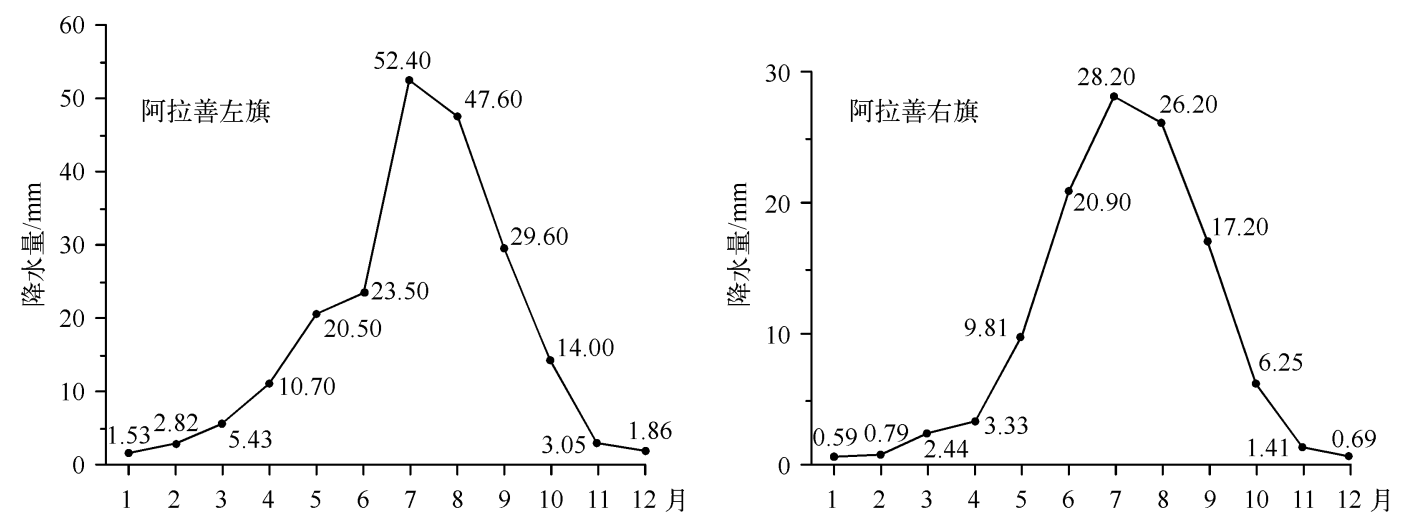

图 5 阿拉善地区 1973-2002 年逐月平均降水量

Fig. 5 Average monthly precipitation in Alashan area during 1973-2002
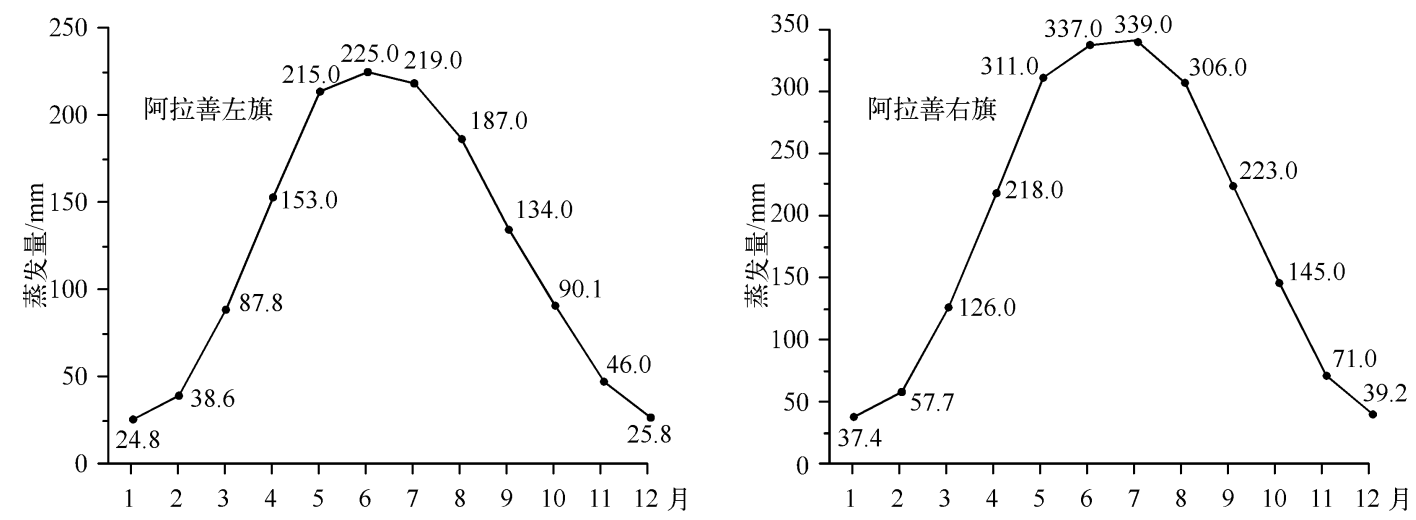

图 6 阿拉善地区 1971-2000 年逐月平均蒸发量

Fig. 6 Average monthly evaporation in Alashan area during 1971 - 2000

伴随着降水量的增加, 湖泊水量也随之增加, 6 月, 降水量达年内最大值, 湖泊水量亦为最大, $4-9$ 月降水量 对全年总降水量的贡献达 $93.93 \%$, 此时期湖泊水量较丰沛, 10 月, 虽然降水量明显降低,但是湖泊水量变化 却不剧烈, 可能是由于 9 月降水量大, 沙漠邻近山区降水通过汇流作用对湖泊进行了一定程度的补给, 在时 间上存在延迟. 10- 12 月期间, 降水量较其他月份大幅减少, 湖泊也剧烈萎缩, 表明在此时间段, 湖泊补给源 的补给量大幅减少. 由于湖泊受到降水及地下水等其他补给方式的共同作用, 这一现象表明, 湖泊补给源的 变动也与降水变动趋势一致. 对于巴丹吉林沙漠而言, 湖泊水量的变化与降水量的变动趋势并不一致 (与降 水量的相关系数为 0.0935 , 与蒸发量的相关系数为 -0.9438$), 3$ 月降水量极低, 而湖泊水量为全年最大. 从 5 月开始, 降水量开始逐渐增加, 5-9 月降水量占全年总降水量的 $92.81 \%, 9-12$ 月期间, 降水量较其他月 份明显减少, 而湖泊水量的变动却并不明显, 这一现象表明, 湖泊补给源补给量的变动情况与降水变动情况 不一致. 因此, 两大沙漠湖泊的补给机制可能存在差别, 腾格里沙漠湖泊水量可能更多地受控于降水或近源 地下水的影响, 腾格里沙漠湖泊可能由贺兰山山区及祁连山东段降水补给, 而巴丹吉林沙漠湖泊受远源地 下水补给作用影响更大, 巴丹吉林沙漠湖泊可能由其南部祁连山山区降水或远源水通过深循环补给.

\section{5 结论}

本文借助 2002 年 6 期 ETM + 遥感影像, 选取腾格里沙漠中部偏东地区沙丘湖泊群作为研究对象, 通过 面向对象方法对湖泊信息进行提取, 建立研究区湖泊季节变化信息, 并对湖泊变化信息进行了季节变化及 区域对比分析, 结论如下: 
1) 腾格里沙漠湖泊随季节变化更替变化明显, 非季节型湖泊年内最大变率达 $30 \%$, 其中冬季至春季、 秋季至冬季湖泊变化最为剧烈, 春、夏季湖泊水量充沛, 冬季为湖泊枯水期. 湖泊季节变化特征与区域降水 量季节变化相一致.

2) 通过对比腾格里沙漠与巴丹吉林沙漠湖泊数量、面积的变化特征及其影响因素, 表明两大沙漠湖泊 的补给机制可能存在差异. 腾格里沙漠湖泊对于降水变化的响应更为敏感, 湖泊水量的变化更多受制于降 水和近源地下水,而巴丹吉林沙漠湖泊变化与远源或深层地下水的关系则更为密切.

由于各年份降水变化情况各异, 可能会导致湖泊季节变动情况呈现出新的特征, 引人多年湖泊变化数据 进行同步对比分析并开展野外定点观测, 通过观测资料进行湖泊水量变化的定量分析, 是下一步研究的重点. 致谢: 本文在写作和修改过程中得到兰州大学地球系统科学研究所李卓仓同学等的帮助,在此一并感谢.

\section{6 参考文献}

[1] 王苏民. 湖泊沉积的信息原理与研究趋势. 见: 张兰生编. 中国生存环境历史演变规律研究. 北京: 海洋出版社, $1993: 22-31$.

[ 2 ] 牛沂芳, 李才兴, 习晓环等. 卫星遥感检测高原湖泊水面变化及与气候变化分析. 干旱区地理, 2008, 31 (2): 284-290.

[ 3 ] 吴艳红, 朱立平, 叶庆华等. 纳木错流域近 30 年来湖泊-冰川变化对气候的响应. 地理学报,2007,62(3):301-312.

[ 4 ] 朱立平, 谢曼平, 吴艳红. 西藏纳木错 1971-2004 年湖泊面积变化及其原因的定量分析. 科学通报, 2010,55(18): 1789-1798.

[ 5 ] 叶庆华, 姚檀栋, 郑红星等. 西藏玛旁雍错流域冰川与湖泊变化及其对气候变化的响应. 地理研究, 2008, 27 (5): 1178-1190.

[ 6 ] Huang ZH, Xue B, Yao SC et al. Lake evolution and its implication for environmental changes in China during 1950 2000. Journal of Geographical Sciences, 2008, 18(2): $131-141$.

[ 7 ] 朱震达,吴 正,刘 恕. 中国沙漠概论. 北京:科学出版社, 1980:71-73.

[ 8 ] 朱金峰,王乃昂, 李卓仑等. 巴丹吉林沙漠湖泊季节变化的遥感监测. 湖泊科学, 2011, 23(4):657-664.

[ 9 ] 丁贞玉,马金珠,何建华. 腾格里沙漠西南缘地下水水化学形成特征及演化. 干旱区地理,2009,32 (6) :948-957.

[10] Smith LC. Satellite remote sensing of river inundation area, stage, and discharge: A review. Hydrological Processes, 1997, 11(10): 1427-1439.

[11] 乔 程, 骆剑承, 盛永伟等. 青藏高原湖泊古今变化的遥感分析一以达则错为例. 湖泊科学, 2010, 22 (1): 98-102.

[12] 曾忠平,卢新海. 城市湖泊时空演变的遥感分析——武汉市为例. 湖泊科学, 2008,20 (5):648-654.

[13] 李 晖,肖鹏峰,冯学智等. 近 30 年三江源地区湖泊变化图谱与面积变化. 湖泊科学, 2010,22(6):862-873.

[14] 王海波,马明国. 基于遥感的湖泊水域动态变化监测研究进展. 遥感技术与应用,2009,24(5):674-684.

[15］张路,廖明生. 一种顾及上下文的遥感影像模糊聚类. 遥感学报,2006,11(1) :58-65.

[16] Blaschke T, Hay GJ. Object-oriented image analysis and scale-space: theory and methods for modeling and evaluating multiscale landscape structure. International Archives of Photogrammetry and Remote Sensing, 2001, 34(4) : 22-29.

[17] 宋 平,刘元波, 刘燕春. 陆地水体参数的卫星遥感反演研究进展. 地球科学进展, 2011, 26(7): 731-740.

[18] Zhang LP, Huang X. Advanced processing techniques for remotely sensed imagery. Journal of Remote Sensing, 2009, 13 (4) : 559-569.

[19] 巫文文,关洪军,段洪涛等. 高矿化度沙漠湖泊水体的光学特性. 湖泊科学, 2011,23(2):209-216.

[20］王乃昂, 李卓仑, 程弘毅等. 阿拉善高原晚第四纪高湖面与大湖期的再探讨. 科学通报, 2011, 56(17) : 1367-1377.

[21] McFeeters SK. The use of normalized difference water index (NDWI) in the delineation of open water features. International Journal of Remote Sensing, 1996, 17(7) : 1425-1432.

[22] 徐涵秋. 利用改进的归一化差异水体指数 (MNDWI) 提取水体信息的研究. 遥感学报, 2005,9(5):589-595.

[23] 问 需,张友静,张元. 利用增强型水体指数 (EWI) 和 GIS 去噪音技术提取半干早地区水系信息的研究. 遥感应 用,2007,6:62-67.

［24］丁 凤.一种基于遥感数据快速提取水体信息的新方法. 遥感技术与应用,2009,24(2):167-171.

[25] 盛 琼, 申双和, 顾 泽. 小型蒸发器的水面蒸发量折算系数. 南京气象学院学报, 2007, 30 (4) :561-565. 